\title{
Myocardial revascularization with miniaturized extracorporeal circulation versus off pump: Evaluation of systemic and myocardial inflammatory response in a prospective randomized study
}

Francesco Formica, MD, ${ }^{\mathrm{a}}$ Francesco Broccolo, MD, ${ }^{\mathrm{b}}$ Antonello Martino, MD, ${ }^{\mathrm{a}}$ Jennifer Sciucchetti, MD, ${ }^{\mathrm{a}}$ Vincenzo Giordano, MD, ${ }^{\mathrm{a}}$ Leonello Avalli, MD, ${ }^{\mathrm{c}}$ Gianluigi Radaelli, MD, ${ }^{\mathrm{c}}$ Orazio Ferro, MD, ${ }^{\mathrm{a}}$ Fabrizio Corti, MD, ${ }^{\mathrm{a}}$ Clementina Cocuzza, MD, PhD, ${ }^{\mathrm{b}}$ and Giovanni Paolini, MD, $\mathrm{PhD}^{\mathrm{a}}$

Objective: This prospective randomized study sought to verify the systemic inflammatory response, inflammatory myocardial damage, and early clinical outcome in coronary surgery with the miniaturized extracorporeal circulation system or on the beating heart.

Methods: Sixty consecutive patients were randomized to miniaturized extracorporeal circulation $(\mathrm{n}=30)$ or off-pump coronary revascularization (off-pump coronary artery bypass grafting, $\mathrm{n}=30$ ). Intraoperative and postoperative data were recorded. Plasma levels of interleukin-6 and tumor necrosis factor- $\alpha$ were measured from systemic blood intraoperatively, at the end of operation, and 24 and 48 hours thereafter. Levels of the same markers and blood lactate were measured from coronary sinus blood intraoperatively to evaluate myocardial inflammation. Markers of myocardial damage were also analyzed.

Results: One patient died in the off-pump coronary artery bypass grafting group. There was no statistical difference in early clinical outcome in both groups. Release of interleukin-6 was higher in the off-pump coronary artery bypass grafting group 24 hours after the operation $(P=.03)$, whereas levels of tumor necrosis factor- $\alpha$ were not different in both groups. Cardiac release of interleukin-6, tumor necrosis factor- $\alpha$, and blood lactate were not different in both groups. Release of troponin $\mathrm{T}$ was not significantly different in both groups. Levels of creatine kinase mass were statistically higher in the miniaturized extracorporeal circulation group than in the off-pump coronary artery bypass grafting group, but only at the end of the operation $(P<.0001)$. Hemoglobin levels were significantly higher in the miniaturized extracorporeal circulation group than in the off-pump coronary artery bypass grafting group after 24 hours $(P=.01)$.

Conclusion: Miniaturized extracorporeal circulation can be considered similar to off-pump surgery in terms of systemic inflammatory response, myocardial inflammation and damage, and early outcome.

Systemic inflammation response syndrome (SIRS) is the main problem linked to the cardiopulmonary bypass (CPB), and its pathogenesis is not well known. It is worth noticing that the blood-air interface and the contact between the blood and the artificial surfaces of the CPB circuit play an important role in initiating SIRS. The inflammatory response is stimulated by a large number of events that result in vascular and tissue damage caused by leukocyte-endothelial interactions mediated by the release of different cytokines, such as interleukin (IL)- 6 and tumor necrosis factor (TNF)- $\alpha$. The clinical manifestations of SIRS are several and may lead to considerable postoperative morbidity and mortality in some patients: Coagulative disorders, ${ }^{1,2}$ myocardial damage, ${ }^{3}$ fluid reten-

From the Cardiac Surgery Clinic, Department of Surgical Science, University of Milano-Bicocca, San Gerardo Hospital, ${ }^{\mathrm{a}}$ Monza, Italy; Department of Clinical Medicine and Prevention, University of Milano-Bicocca, ${ }^{\mathrm{b}}$ Milan, Italy; and Cardiac Surgery Intensive Care, San Gerardo Hospital, ${ }^{\mathrm{c}}$ Monza, Italy.

Received for publication Feb 26, 2008; revisions received Sept 6, 2008; accepted for publication Sept 19, 2008.

Address for reprints: Francesco Formica, MD, Clinica Cardiochirurgica, Ospedale San Gerardo, Via Pergolesi 33, 20052, Monza (MI) Italy (E-mail: francesco_formica@ fastwebnet.it).

J Thorac Cardiovasc Surg 2009;137:1206-12

$0022-5223 / \$ 36.00$

Copyright (c) 2009 by The American Association for Thoracic Surgery doi: $10.1016 /$ j.jtcvs.2008.09.074 tion, thromboembolism, and organ dysfunction ${ }^{3,4-9}$ may negatively affect the postoperative course. Recent articles report better results in off-pump coronary artery bypass grafting (OPCABG) compared with CPB in terms of myocardial, renal and cerebral organ preservation, ${ }^{10-14}$ and SIRS. ${ }^{15}$ However, OPCABG has some important drawbacks, such as incomplete revascularization, low graft patency, and hemodynamic instability occurring during the displacement of the heart. ${ }^{16,17}$ New concepts in the management and materials of CPB have been developed, and efforts are focused on reducing tubing surface area, improving surface coating circuit, eliminating blood-air contact, using closed cardiotomy, and improving oxygenators to obtain a low-risk CPB system.

The miniaturized extracorporeal circulation (MECC) system should dramatically reduce the side effects caused by $\mathrm{CPB}$, thus resulting in a low inflammation response as for OPCABG and allowing a complete myocardial revascularization as for standard CPB.

Many authors have already described the benefit of MECC versus standard CPB in terms of reduced myocardial damage, less coagulative disorder, and less inflammatory response. ${ }^{18-21}$ On the other hand, few articles ${ }^{22,23}$ have recently compared the MECC procedure with the OPCABG procedure. 


\begin{tabular}{|c|c|}
\hline \multicolumn{2}{|c|}{ Abbreviations and Acronyms } \\
\hline $\mathrm{CK}$ & $=$ creatine kinase \\
\hline $\mathrm{CPB}$ & $=$ cardiopulmonary bypass \\
\hline CS & $=$ coronary sinus \\
\hline IL & $=$ interleukin \\
\hline MECC & $=$ miniaturized extracorporeal circulation \\
\hline OPCABC & $\begin{aligned} & \text { off-pump coronary artery bypass } \\
& \text { grafting }\end{aligned}$ \\
\hline SIRS & $\begin{aligned}= & \text { systemic inflammation response } \\
& \text { syndrome }\end{aligned}$ \\
\hline TNF & $=$ tumor necrosis factor \\
\hline TnT & $=\operatorname{troponin} \mathrm{T}$ \\
\hline
\end{tabular}

This prospective randomized study evaluated the systemic inflammatory response, myocardial necrosis, and myocardial inflammation by comparing patients with coronary artery disease who underwent operation with the MECC system or on the beating heart. For this purpose, cytokines such as IL-6 and TNF- $\alpha$ and biochemical measurements from both systemic and coronary sinus (CS) blood were intraoperatively and postoperatively investigated.

\section{MATERIALS AND METHODS Patient Selection}

From April 2007 to October 2007, 60 consecutive patients with coronary disease who were technically suitable for MECC or OPCABG were enrolled in this study after providing written informed consent. The patients were randomly allocated into 2 groups: MECC $(\mathrm{n}=30)$ or OPCABG $(\mathrm{n}=$ 30). Inclusion criteria were as follows: primary and isolated CABG operation; at least 2-vessel disease; ejection fraction of $40 \%$ or more; 30 to 85 years of age; serum creatinine less than $1.8 \mathrm{mg} / 100 \mathrm{~mL}$; and absence of acute or chronic inflammatory syndrome. Exclusion criteria were as follows: small, calcified, and intramyocardial coronaries; recent or current steroid treatments; urgent or salvage operation; recent myocardial infarction ( $<10$ days); unstable angina with intravenous medications; and conversion of OPCABG to standard CPB during the operation. A randomization list was generated by a computer algorithm. This prospective randomized study was approved by the local ethics committee.

\section{Sample Collection}

Blood samples were collected to analyze 1) the myocardial damage: troponin $\mathrm{T}(\mathrm{TnT})$, myoglobin, total creatine kinase (CK), and CK mass; 2) the inflammatory response: IL-6, TNF- $\alpha$, C-reactive protein, leukocyte, neutrophil, and monocyte cell counts; 3 ) the hemodilution: hematocrit and haemoglobin; and 4) the coagulative disorder: fibrinogen and platelet count. Blood samples for myocardial damage, hemodilution, and coagulative disorder were serially collected the day before surgery (T0), at the end of operation (T1), 24 hours after operation (T2), and 48 hours after operation (T3). Blood lactate and cytokine levels were analyzed before the anesthesia induction (T0), before CPB initiation in the MECC group or before the first distal anastomosis in the OPCABG group (T1), 5 minutes after aortic clamp removal in the MECC group or 5 minutes after the last distal anastomosis in the OPCABG group (T2), at the end of operation (T3), 12 hours after operation (T4), and 24 hours after operation (T5). Blood lactate, IL-6, TNF- $\alpha$, hemoglobin, and hematocrit were analyzed by contemporaneously taking 2 blood samples from the radial artery and the CS before instituting CPB in the MECC group or before the first distal anastomosis in the OPCABG group (T1) and 5 minutes after aortic clamp removal in the MECC group or after the last distal anastomosis in the OPCABG group (T2). In both groups, a CS cannula for cardioplegia delivery (Edwards Lifesciences, Irvine, Calif) was used for taking the blood samples. In the MECC group, the sinus cannula was kept inside the CS throughout the period of aortic clamping, whereas in the OPCABG group the cannula was used for only the blood sample collection.

\section{Surgical Strategy}

Anesthesia protocol was the same in all patients. Anesthesia was induced with fentanyl 0.005 to $0.01 \mathrm{mg} / \mathrm{kg}$, midazolam 0.08 to $0.2 \mathrm{mg} / \mathrm{kg}$, and pancuronium $0.1 \mathrm{mg} / \mathrm{kg}$, and was maintained with propofol 3 to $6 \mathrm{mg} / \mathrm{kg} / \mathrm{h}$, fentanyl, sevoflurane, and pancuronium as needed.

All patients underwent operation via a full median sternotomy. The left internal thoracic artery (ITA) was harvested in all patients and always anastomosed on the left anterior descending artery. In those patients who received both thoracic arteries, the right ITA was anastomosed on the marginal branch. Total arterial revascularization was obtained with bilateral ITAs and the left radial artery. Because pedicle thoracic arteries and the left ITA on the left anterior descending artery are preferred to other alternatives in our institution (Cardiac Surgery Clinic at San Gerardo Hospital), no patients received composite grafts or right ITAs on the left anterior descending artery.

The MECC is a Bioline fully heparin-coated system that includes a centrifugal pump Rotaflow RF-32 (Maquet-Jostra AG, Hirrlingen, Germany) and a continuous diffusion polymethylpentene membrane oxygenator Quadrox D with an integrated heat exchanger, (Maquet-Jostra AG, Hirrlingen, Germany). The system did not include any cardiotomy, and the pericardial shed blood was sucked into a cell saver device (CAIS Fresenius Hemocare, Bad Homburg, Germany) that was also used in the OPCABG group. An arterial filter Quart (Maquet-Jostra AG, Hirrlingen, Germany) was positioned between the oxygenator and the arterial line to remove microbubbles; a venous bubble trap VBT 160 (Maquet-Jostra AG, Hirrlingen, Germany) was allocated between the venous line and the centrifugal pump to remove air bubbles coming from the vein line or the aortic root vent. The system was primed with $1000 \mathrm{~mL}$ of Ringer's lactate solution, $100 \mathrm{~mL}$ of $18 \%$ mannitol, and $500 \mathrm{~mL}$ of $6 \%$ hydroxyethyl starch (Voluven, Fresenius Kabi, Bad Homburg, Germany). The effective prime was approximately $650 \mathrm{~mL}$. MECC was instituted by ascending aorta and right atrium cannulation, and the management was as follows: a blood flow rate of $2.4 \mathrm{~L} / \mathrm{min} /$ $\mathrm{m}^{2}$, mean systolic pressure ranging between 60 and $80 \mathrm{~mm} \mathrm{Hg}$, and corporeal temperature of $35^{\circ} \mathrm{C}$. Heparin was given at a dose of $3 \mathrm{mg} / \mathrm{kg}$ with an activated clotting time ranging from 350 to 400 seconds. Cardiac arrest was obtained through a cold $\left(4^{\circ} \mathrm{C}\right)$ intermittent blood cardioplegic solution injected via the aortic root and CS. Cardioplegia maintenance was repeated every 18 to 20 minutes. Protamine sulphate was given to neutralize the heparin. The circuit was $3 / 8$ size for all length, and the effective total length was less than $1 \mathrm{~m}$. All distal and proximal anastomoses were performed under a single total aortic crossclamping time.

In the OPCABG group, heparin was given at a dose of $1.5 \mathrm{mg} / \mathrm{kg}$ with an activated clotting time target of 250 seconds. The anastomosis between the left ITA and the left anterior descending artery was always performed first, and then the proximal anastomosis in the aortic root was performed with the HeartString II Proximal Seal System device (Maquet AG, Hirrlingen, Germany). The distal anastomosis on the marginal branches and right coronary system was finally done. The heart was stabilized using the Medtronic Octopus device (Medtronic, Minneapolis, Minn), and the marginal branches of the left circumflex and right coronary arteries were exposed by a long strip anchored to a deep pericardial stitch with a tourniquet. All operations were performed by the same senior surgeon (F.F.).

\section{Sample Storage}

The samples for IL- 6 and TNF- $\alpha$ were immediately cooled to $4^{\circ} \mathrm{C}$ and centrifuged at $5000 \mathrm{rpm}$ for 20 minutes at $4^{\circ} \mathrm{C}$. The supernatant was 
TABLE 1. Patient characteristics

\begin{tabular}{|c|c|c|c|}
\hline Variables & $\begin{array}{c}\text { MECC system } \\
\quad(\mathbf{n}=\mathbf{3 0})\end{array}$ & $\begin{array}{c}\text { OPCABG } \\
(\mathbf{n}=\mathbf{3 0})\end{array}$ & $\boldsymbol{P}$ \\
\hline Gender (male) & $23(76.6 \%)$ & $18(60 \%)$ & .07 \\
\hline Mean age (y) & $61.2 \pm 10.4(35-76)$ & $70 \pm 7.7(56-83)$ & .05 \\
\hline Ejection fraction $(\%)$ & $57 \pm 7(42-67)$ & $56.4 \pm 9.2(40-71)$ & .08 \\
\hline Left main disease & $12(40 \%)$ & $8(26.6 \%)$ & .50 \\
\hline Vessel disease & $2.5 \pm 0.51$ & $2.47 \pm 0.51$ & .30 \\
\hline BSA & $1.85 \pm 0.16$ & $1.76 \pm 0.21$ & .10 \\
\hline BMI & $25.5 \pm 1.6$ & $26.3 \pm 4.8$ & .80 \\
\hline Hyperlipidemia & $21(70 \%)$ & $17(56.6 \%)$ & .50 \\
\hline Hypertension & $17(56.6 \%)$ & $22(73.3 \%)$ & .10 \\
\hline Diabetes mellitus & $7(23.3 \%)$ & $11(36.6 \%)$ & .60 \\
\hline Smoking & $14(60 \%)$ & $9(46.7 \%)$ & .10 \\
\hline COPD & $2(6.6 \%)$ & $4(13.3 \%)$ & .20 \\
\hline Carotid disease & $2(6.6 \%)$ & $4(13.3 \%)$ & .20 \\
\hline
\end{tabular}

$B S A$, Body surface area; $B M I$, body mass index; $C O P D$, chronic obstructive pulmonary disease; $M E C C$, miniaturized extracorporeal circulation; $O P C A B G$, off-pump coronary artery bypass grafting.

separated and stored at $-80^{\circ} \mathrm{C}$. IL- 6 and TNF- $\alpha$ were measured by an enzyme-linked immunosorbent assay using a commercial kit (R\&D System, DuoSet ELISA, Minneapolis, Minn) with a minimum detectable dose of $5.0 \mathrm{pg} / \mathrm{mL}$. Measurements of TnT, myoglobin, and CK-MB mass were done using an Elecsys 2010 analyzer (Roche Diagnostics, Mannheim, Germany). These assays are based on electrochemiluminescence immunoassay technology (Roche Diagnostics, Mannheim, Germany). The detection limit was $0.01 \mu \mathrm{g} / \mathrm{L}$ for TnT, $15 \mu \mathrm{g} / \mathrm{L}$ for myoglobin, and $0.1 \mu \mathrm{g} / \mathrm{L}$ for CK mass.

\section{Statistical Analysis}

Data are expressed as the mean \pm standard deviation for continuous variables. The categoric variables are expressed as percentages. Unpaired $t$ and chi-square tests were applied to compare clinical variables. The MannWhitney $U$ test was used for those variables that were not normally distributed. Analysis of continues variables over time were analyzed by applying the 2-way analysis of variance for repeated measures. All data were prospectively included in a statistical database and analyzed with the Statistical Package for the Social Sciences (15.0 for Windows; SPSS Inc, Chicago, Ill).

\section{RESULTS \\ Clinical Outcomes}

No patient was withdrawn from the study. Preoperative characteristics (Table 1) did not differ between groups. Perioperative and postoperative parameters (Table 2) were also similar between groups except for the use of bilateral internal thoracic arteries, which was significantly lower in the OPCABG group than in the MECC group. There was no statistical significance in both groups regarding postoperative bleeding, requirement of blood transfusions, and incidence of atrial fibrillation. One patient treated with MECC required the use of an intraaortic balloon pump after weaning from extracorporeal circulation because of a new onset of lateral transmural ischemia despite the use of inotropic drugs and a coronary vasodilator. The patient was supported with an intra-aortic balloon pump for 48 hours and was discharged on the ninth postoperative day. One patient in the OPCABG group died of acute severe respiratory disease on the fifth postoperative day. No patients had postoperative cerebro-
TABLE 2. Perioperative and postoperative data

\begin{tabular}{|c|c|c|c|}
\hline Variables & $\begin{array}{l}\text { MECC system } \\
\quad(\mathbf{n}=\mathbf{3 0})\end{array}$ & $\begin{array}{c}\text { OPCABG } \\
(\mathbf{n}=\mathbf{3 0})\end{array}$ & $P$ \\
\hline No. of distal anastomoses & $2.70 \pm 0.65$ & $2.53 \pm 0.61$ & .30 \\
\hline BITAs & $18(60 \%)$ & $5(8.3 \%)$ & .01 \\
\hline CPB time $(\mathrm{min})$ & $87.1 \pm 19$ & - & - \\
\hline $\begin{array}{l}\text { Aortic crossclamping } \\
\text { time }(\mathrm{min})\end{array}$ & $67.15 \pm 15.21$ & - & - \\
\hline Intubation time & $10.4 \pm 6.9$ & $10 \pm 3.2$ & .82 \\
\hline ICU stay (h) & $27.65 \pm 23.2$ & $25.37 \pm 15.1$ & .72 \\
\hline Bleeding within $12 \mathrm{~h}$ & $426 \pm 246.48$ & $414.21 \pm 198.58$ & .87 \\
\hline $\begin{array}{l}\text { Reexploration for } \\
\text { bleeding/tamponade }\end{array}$ & 0 & 0 & 1 \\
\hline IABP & $1(1.6 \%)$ & 0 & .81 \\
\hline Atrial fibrillation & $12(40 \%)$ & $7(23.3 \%)$ & .3 \\
\hline $\begin{array}{l}\text { Patients receiving } \\
\text { transfusion during } \\
\text { hospitalization }\end{array}$ & $10(33.3 \%)$ & $11(36.6 \%)$ & .9 \\
\hline Hospital stay (d) & $5.05 \pm 1.39$ & $5.44 \pm 1.29$ & .39 \\
\hline Hospital mortality & 0 & $1(1.6 \%)$ & .81 \\
\hline
\end{tabular}

$B I T A$, Bilateral internal thoracic artery; $C P B$, cardiopulmonary bypass; $O R$, operating room; $I C U$, intensive cardiac unit; IABP, intra-aortic balloon pump; $M E C C$, miniaturized extracorporeal circulation; $O P C A B G$, off-pump coronary artery bypass grafting.

vascular accident, low cardiac output syndrome, or acute renal failure.

\section{Myocardial Damage}

No patient experienced a new postoperative myocardial infarction defined as new $\mathrm{Q}$ waves of more than $0.05 \mathrm{~ms}$ and a reduction in $\mathrm{R}$ waves of more than $25 \%$ in at least 2 electrocardiogram leads, as well as new echocardiographic akinesia or hypokinesia area. TnT and myoglobin increased regularly over time without difference between the 2 groups. TnT peaked at 24 hours and then decreased after 48 hours; the myoglobin peak was recorded at the end of the operation and decreased after. Levels of total CK and CK-mass serum were statistically higher in the MECC group than in the OPCABG group, but only at the end of the operation (total CK: $204.5 \pm 103.1 \mathrm{U} / \mathrm{L}$ vs $143.4 \pm 79.9 \mathrm{U} / \mathrm{L}, P=.04$; CK-mass: $15.7 \pm 5.2 \mu \mathrm{g} / \mathrm{L}$ vs $9.5 \pm 3.6 \mu \mathrm{g} / \mathrm{L}, P<.0001)$; the difference disappeared 24 and 48 hours after the operation.

\section{Inflammatory Response}

IL-6 plasma levels increased in both groups during and after the operation. IL-6 levels were significantly higher in the OPCABG group than in the MECC group 24 hours after the operation $(P=.03$; Figure $1, A)$. TNF- $\alpha$ levels were higher in the OPCABG group than in the MECC group at each time point, although no statistical difference was recorded; moreover, there was a decrease at the end of the operation in both groups (Figure 1, B). Transmyocardial gradient was calculated by the difference between arterial and CS levels, and the negative gradient was interpreted as the cardiac release of cytokines into the coronary circulation. There were no 

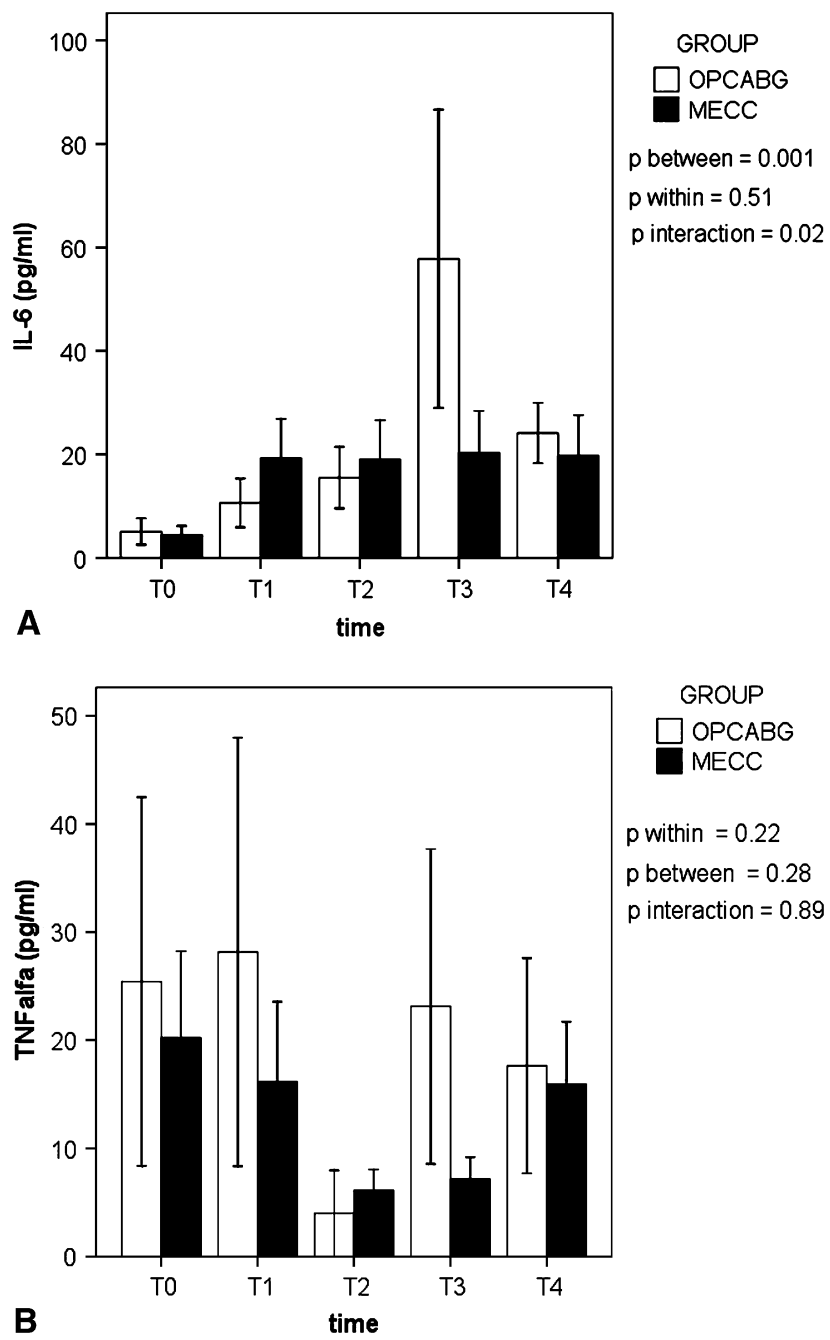

FIGURE 1. A, Time course of IL-6 in patients undergoing OPCABG or MECC. B, Time course of TNF- $\alpha$ in patients undergoing OPCABG or MECC. $\mathrm{T} 0=$ before $\mathrm{CPB}$ initiation in MECC group or before the first distal anastomosis in OPCABG group; $\mathrm{T} 1=5$ minutes after aortic clamp removal in MECC group or 5 minutes after the last distal anastomosis in OPCABG group; T2 $=$ end of operation; $\mathrm{T} 3=24$ hours; T $=48$ hours. Data are expressed as means \pm standard error of the mean (SEM). IL, Interleukin; $T N F$, tumor necrosis factor.

statistical differences in transmyocardial gradients between the 2 groups at T1. Cardiac release of IL- 6 was higher in the OPCABG group than in the MECC group at T2, but without significant difference (Figure 2, $A$ ); at the same time point, cardiac release of TNF- $\alpha$ was more evident in the MECC group than in the OPCABG group, but without significant difference (Figure 2, B). Monocyte cell levels decreased at the end of the operation and then increased 24 and 48 hours after the operation (Figure 3).

\section{Hemodilution}

Hemoglobin levels were significantly higher in the MECC group than in the OPCABG group 24 hours after the opera-
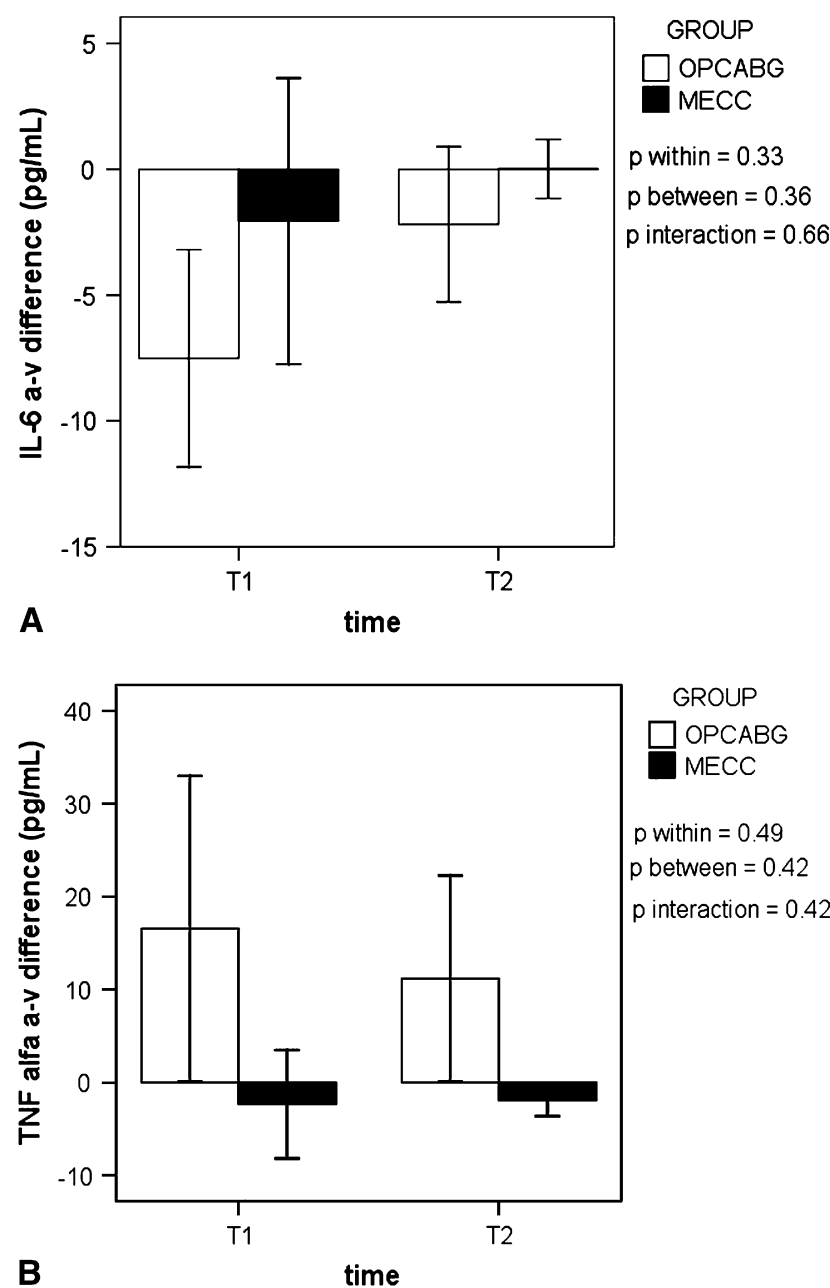

FIGURE 2. A, Arteriovenous difference of IL-6-from CS in patients undergoing OPCABG or MECC. B, Arteriovenous difference of TNF- $\alpha$ from CS in patients undergoing OPCABG or MECC. T0 = before $\mathrm{CPB}$ initiation in MECC group or before the first distal anastomosis in OPCABG group; $\mathrm{T} 1=5$ minutes after aortic clamp removal in MECC group or $5 \mathrm{~min}$ utes after the last distal anastomosis in OPCABG group. Data are expressed as means \pm SEM. $I L$, Interleukin; $T N F$, tumor necrosis factor.

tion $(P=.01$; Table 2$)$, despite the fact that no significant difference was observed between the groups in terms of the number of patients receiving transfusion and the number of red cell blood units transfused per patient at the same time point. Although a statistical difference in arterial systemic hemoglobin was observed in both groups 5 minutes after aortic clamp removal in the MECC group and after the last distal anastomosis in the OPCABG group $(8.8 \pm 0.9 \mathrm{~g} / 100 \mathrm{~mL}$ vs $9.9 \pm 1.6 \mathrm{~g} / 100 \mathrm{~mL}, P=.012$ ), no difference was reported in CS hemoglobin in both groups at the same time $(9 \pm 1.1 \mathrm{~g} /$ $100 \mathrm{~mL}$ vs $9.8 \pm 1.6 \mathrm{~g} / 100 \mathrm{~mL}$, respectively, $P=.09$ ).

\section{Systemic and Cardiac Blood Lactate}

The time course of systemic blood lactate increased in both groups during and after the operation. The blood lactate 


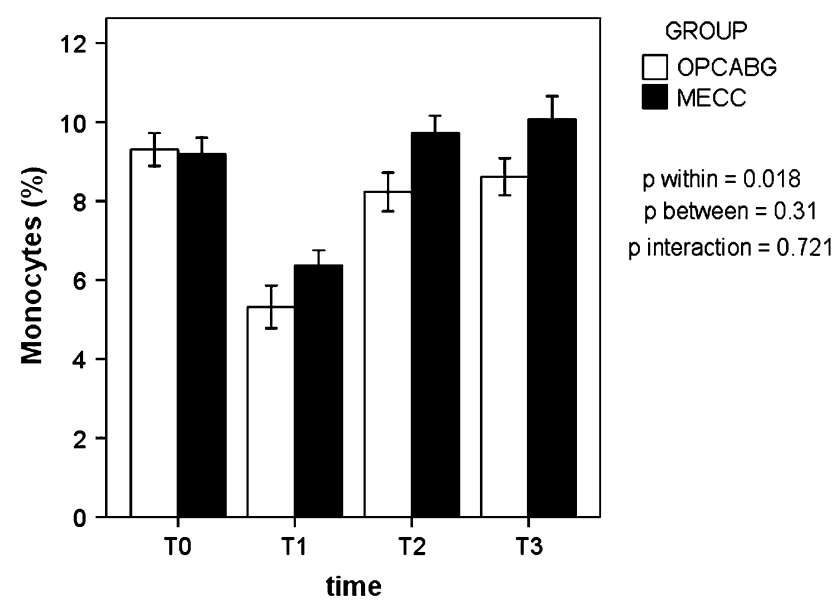

FIGURE 3. Time course of monocyte count in patients undergoing OPCABG or MECC. $\mathrm{T} 0=$ preoperative; $\mathrm{T} 1=$ end of operation; $\mathrm{T} 2=24$ hours; $\mathrm{T} 3=48$ hours. Data are expressed as means \pm SEM.

peaked in the MECC group at the end of the operation, and there was no significant difference in the OPCABG group. At 12 hours, the blood lactate release in the MECC group was significantly lower than in the OPCABG group $(P=$ .009; Figure 4, A). Cardiac blood lactate from the CS increased significantly in both groups intraoperatively and showed higher levels in the MECC group than in the OPCABG group, although no statistical differences were detected (Figure 4, B).

\section{DISCUSSION}

The MECC system is a new concept of CPB that was recently introduced into clinical practice. ${ }^{24}$ The main goal of MECC was to create a simplified system to reduce the deleterious effects of conventional $\mathrm{CPB} .^{25}$ The MECC system links the concept of increased biocompatibility using a heparin-coated circuit with reduced air-blood interface, eliminating the cardiotomy. Many authors have conducted randomized studies comparing the MECC system with conventional $\mathrm{CPB}$ in patients undergoing $\mathrm{CABG}$. Fromes and colleagues ${ }^{18}$ found a reduced inflammatory activation and a lower S-100 protein release in the MECC group. Beghi and colleagues ${ }^{26}$ reported no statistical difference in TnT and IL-6 evolution in the MEEC group. Wiesenack and colleagues $^{24}$ reported their 4 years of experience in using MECC and showed a reduced incidence of postoperative complications and a lower blood lactate release. The recent experiences of many authors with MECC in patients undergoing CABG have been encouraging, and some have extended the MECC system in aortic valve replacement, reporting reduced inflammatory response ${ }^{27}$ and better myocardial protection. ${ }^{28}$

Few authors have compared MECC with OPCABG. In a prospective randomized study of 150 patients per group, Mazzei and coworkers ${ }^{23}$ demonstrated that the MECC and OPCABG groups had similar IL-6, S-100 protein, and total

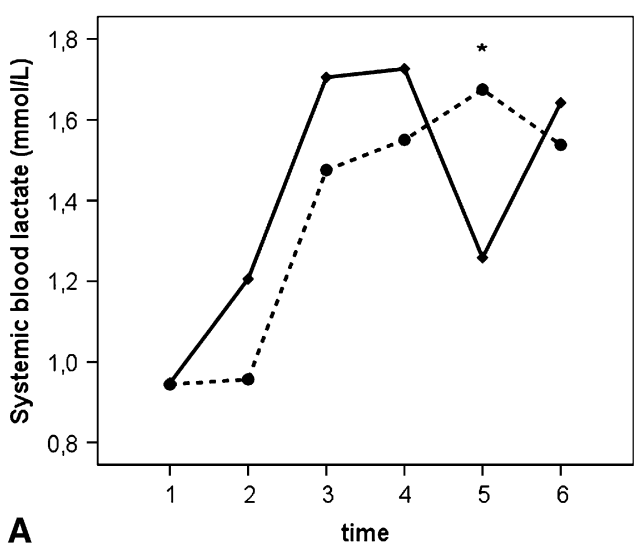

Group - OPCABG - MECC

${ }^{\star} p=0.009$

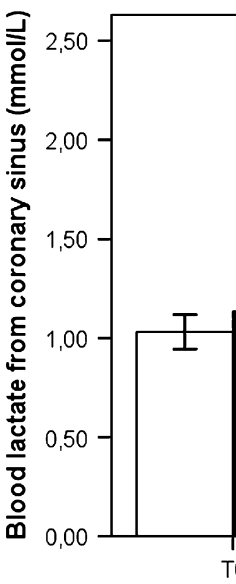

B

FIGURE 4. A, Time course of systemic blood lactate in patients undergoing OPCABG or MECC. T0 = before CPB initiation in MECC group or before the first distal anastomosis in OPCABG group; T1 $=5$ minutes after aortic clamp removal in MECC group or 5 minutes after the last distal anastomosis in OPCABG group; $\mathrm{T} 2=$ end of operation; $\mathrm{T} 3,=12$ hours; $\mathrm{T} 4=$ 24 hours; T5 $=48$ hours. B, Time course of blood lactate from CS in patients undergoing OPCABG or MECC. T0 = before $\mathrm{CPB}$ initiation in MECC group or before the first distal anastomosis in OPCABG group; $\mathrm{T} 1=5$ minutes after aortic clamp removal in MECC group or 5 minutes after the last distal anastomosis in OPCABG group. Data are expressed as means \pm SEM.

CK release. They assert that even if MECC is associated with cardioplegic arrest, the 2 procedures could be considered equivalent in terms of myocardial and brain damage, inflammatory response, early mortality, and 1-year morbidity and mortality.

To the best of our knowledge, there are no data published on the myocardial inflammation in patients undergoing operation with the MECC system measured by collecting blood samples through the CS. Therefore, we wanted to observe whether the MECC system preserves myocardial inflammation and reduces ischemic/reperfusion injury by measuring inflammatory cytokines (eg, IL-6 and TNF- $\alpha$ ) and lactate levels directly from the CS. 
IL-6 and TNF- $\alpha$ are 2 potent proinflammatory cytokines with detrimental systemic myocardium effects. IL-6 increases in response to major surgeries, including cardiac surgery with $\mathrm{CPB}$, and is probably released by mononuclear macrophages. ${ }^{18}$ TNF- $\alpha$ has a negative inotrope effect, and the myocardium is probably the source of this inflammatory cytokine after ischemia/reperfusion injury. A subset of mature blood monocyte cells are recognized as a major source of TNF- $\alpha{ }^{29,30}$ We observed no significant differences between the 2 groups in terms of systemic and cardiac IL-6 and TNF- $\alpha$ release. Systemic blood TNF- $\alpha$ levels were higher in the OPCABG group than in the MECC group during and after the operation, but without statistic difference over time. The lowest peak of TNF- $\alpha$ levels recorded in both groups at the end of the operation should be considered with regard to the monocyte count. The increase of systemic IL-6 was observed in both groups with higher levels after 24 hours in the OPCABG group. Because the monocyte cells are probably a major source of IL-6, plasma release of this cytokine has to correlate with the monocyte count. We cannot demonstrate any statistical difference between the 2 groups in terms of transmyocardial gradient of both cytokines. A lower arteriovenous difference was recorded in both TNF- $\alpha$ and IL- 6 between the 2 groups at T2. We suggest that the release of these inflammatory cytokines is not affected by the MECC system, aortic crossclamping, or OPCABG. Rather, we consider the surgical procedure per se as the main cause of cytokine release. Moreover, the major surgical stress seems to trigger a lower monocyte activation that we observed in both groups at the end of the operation. We cannot explain the smaller, although not significant, release of cytokines with the MECC system. Perhaps the high performing oxygenator, the centrifugal pump with a low prime, and the high biocompatibility of the circuit play important roles in reducing SIRS and myocardial damage. Moreover, all patients who underwent operation with the MECC system received aortic crossclamping with an intrinsic risk of ischemic/reperfusion injury, which was not observed. Because SIRS and myocardial damage are low in those who undergo operation with the MECC system, it can be argued that MECC may protect the myocardium during the aortic crossclamping period. The absence of a statistical difference in the CS blood lactate release and the transmyocardial gradient of cytokines after aortic clamp removal or the last anastomosis should indicate a low myocardial injury in the MECC group. In regard to the hemodilution, we observed an intraoperative systemic hemodilution in the MECC group after aortic clamp removal, whereas no difference was observed when the CS hemoglobin was analyzed. It can be speculated that although the MECC system caused a more systemic hemodilution than off pump, it was not particularly severe and therefore did not cause hemodilution in CS blood compared with OPCABG. It can be argued that oxygen delivery during the aortic crossclamping period is safe and effective in the MECC system.

There is increasing evidence that OPCABG causes reduced $\mathrm{CK}-\mathrm{MB}$ and troponin serum concentration ${ }^{17,25}$ when compared with standard CPB. One of our findings in the present study is the absence of a statistical difference in TnT and myoglobin release over time, whereas differences were found in total $\mathrm{CK}$ and $\mathrm{CK}-\mathrm{MB}$ release at the end of operation only. These differences can be attributed to a majority of patients who received double ITAs in the MECC group. Therefore, the regular increase of these myocardial necrosis markers could be attributed to cardiac manipulation, thoracic artery harvesting, macrosurgical and microsurgical trauma induced by suction stabilization, cell-saver blood reinfusion at the end of operation, and blower-induced air embolization.

\section{CONCLUSIONS}

The findings of this study suggest that MECC and OPCABG should be considered similar in terms of SIRS, myocardial inflammation and damage, postoperative transfusion, and early outcome. Thus, considering the current drawback of the OPCABG procedure, it can be argued that MECC can be extensively used in all patients with multivessel disease in whom OPCABG could have more operative risks. More randomized studies are mandatory to confirm the safety and reproducibility of the MECC system not only in low-risk patients with coronary disease but also in high-risk patients with coronary disease, such as those undergoing a repeat CABG operation or those with moderate or severe myocardial dysfunction that is progressively increasing.

The authors thank Gabriella Giannini and Giorgia Pavan for editing assistance during the preparation of the article, Dr Nicolò Patroniti for statistical support, and Maria Muratore, Cristina Costa, Carla Gambarini, and Rosa Caruso for support during data collection.

\section{References}

1. Paparella D, Brister SJ, Buchanan MR. Coagulation disorders of cardiopulmonary bypass: a review. Intensive Care Med. 2004;30:1873-81.

2. Dixon B, Santamaria J, Campbell D. Coagulation activation and organ dysfunction following cardiac surgery. Chest. 2005;128:229-36.

3. Anselmi A, Abbate A, Girola F, Nasso G, Biondi-Zoccai GG, Possati G, et al. Myocardial ischemia, stunning, inflammation, and apoptosis during cardiac surgery: a review of evidence. Eur J Cardiothorac Surg. 2004;25:304-11.

4. Haugen O, Farstad M, Kvalheim V, Hammersborg S, Husby P. Intraoperative fluid balance during cardiopulmonary bypass: effects of different mean arterial pressures. Perfusion. 2007;22:273-8.

5. Kvalheim VL, Rynning SE, Farstad M, Haugen O, Nygreen E, Mongstad A, et al Fluid overload during cardiopulmonary bypass is effectively reduced by a continuous infusion of hypertonic saline/dextran (HSD). Scand Cardiovasc J. 2007;25: $1-8$.

6. Haugen O, Farstad M, Kvalheim V, Bøe O, Husby P. Elevated flow rate during cardiopulmonary bypass is associated with fluid accumulation. $J$ Thorac Cardiovasc Surg. 2007;134:587-93.

7. Selnes OA, Grega MA, Bailey MM, Pham L, Zeger S, Baumgartner WA, et al. Neurocognitive outcomes 3 years after coronary artery bypass graft surgery: a controlled study. Ann Thorac Surg. 2007;84:1885-96. 
8. Korn-Lubetzki I, Oren A, Asher E, Dano M, Bitran D, Fink D, et al. Strokes after cardiac surgery: mostly right hemispheric ischemic with mild residual damage. J Neurol. 2007;254:1708-13.

9. Morariu AM, Loef BG, Aarts LP, Rietman GW, Rakhorst G, van Oeveren W, et al. Dexamethasone: benefit and prejudice for patients undergoing on-pump coronary artery bypass grafting: a study on myocardial, pulmonary, renal, intestinal, and hepatic injury. Chest. 2005;128:2677-87.

10. Li S, Price R, Phiroz D, Swan K, Crane TA. Systemic inflammatory response during cardiopulmonary bypass and strategies. J Extra Corpor Technol. 2005;37: $180-8$.

11. Ascione R, Lloyd CT, Gomes WJ, Caputo M, Bryan AJ, Angelini GD. Beating versus arrested heart revascularization: evaluation of myocardial function in a prospective randomized study. Eur J Cardiothorac Surg. 1999;15:685-90.

12. Ascione R, Lloyd CT, Underwood MJ, Gomes WJ, Angelini GD. On-pump versus off-pump coronary revascularization: evaluation of renal function. Ann Thorac Surg. 1999;68:493-8.

13. Chernov VI, Efimova NY, Efimova IY, Akhmedov SD, Lishmanov YB. Shortterm and long-term cognitive function and cerebral perfusion in off-pump and on-pump coronary artery bypass patients. Eur J Cardiothorac Surg. 2006;29: 74-81.

14. Ascione R, Ghosh A, Reeves BC, Arnold J, Potts M, Shah A, et al. Retinal and cerebral microembolization during coronary artery bypass surgery: a randomized, controlled trial. Circulation. 2005;112:3833-8.

15. Ascione R, Lloyd CT, Underwood MJ, Lotto AA, Pitsis AA, Angelini GD. Inflammatory response after coronary revascularization with or without cardiopulmonary bypass. Ann Thorac Surg. 2000;69:1198-204.

16. Caputo M, Reeves BC, Rajkaruna C, Awair H, Angelini GD. Incomplete revascularization during OPCAB surgery is associated with reduced mid-term eventfree survival. Ann Thorac Surg. 2005;80:2141-7.

17. Ascione R, Caputo M, Angelini GD. Off-pump coronary artery bypass grafting: not a flash in the pan. Ann Thorac Surg. 2003;75:306-13.

18. Fromes Y, Gaillard D, Ponzio O, Chauffert M, Gerhardt MF, Deleuze P, et al. Reduction of the inflammatory response following coronary bypass grafting with total minimal extracorporeal circulation. Eur J Cardiothorac Surg. 2002; 22:527-33.

19. Immer FF, Ackermann A, Gygax E, Stalder M, Englberger L, Eckstein FS, et al. Minimal extracorporeal circulation is a promising technique for coronary artery bypass grafting. Ann Thorac Surg. 2007;84:1515-20.
20. Agati S, Ciccarello G, Trimarchi ES, Grasso D, Trimarchi G, Di Stefano S, et al. Extracorporeal circulation, optimized: a pilot study. Artif Organs. 2007;31: 377-83.

21. Skrabal CA, Steinhoff G, Liebold A. Minimizing cardiopulmonary bypass attenuates myocardial damage after cardiac surgery. ASAIO J. 2007;53:32-5.

22. Wippermann J, Albes JM, Hartrumpf M, Kaluza M, Vollandt R, Bruhin R, et al. Comparison of minimally invasive closed circuit extracorporeal circulation with conventional cardiopulmonary bypass and with off-pump technique in CABG patients: selected parameters of coagulation and inflammatory system. Eur $J$ Cardiothorac Surg. 2005;28:127-32.

23. Mazzei V, Nasso G, Salamone G, Castorino F, Tommasini A, Anselmi A. Prospective randomized comparison of coronary bypass grafting with minimal extracorporeal circulation system (MECC) versus off-pump coronary surgery. Circulation. 2007;116:1761-7.

24. Wiesenack C, Liebold A, Philipp A, Ritzka M, Koppenberg J, Birnbaum DE, et al. Four years' experience with a miniaturized extracorporeal circulation system and its influence on clinical outcome. Artif Organs. 2004;28:1082-8.

25. Remadi JP, Rakotoarivelo Z, Marticho P, Benamar A. Prospective randomized study comparing coronary artery bypass grafting with the new mini-extracorporeal circulation Jostra System or with a standard cardiopulmonary bypass. Am Heart J. 2006;151:198.

26. Beghi C, Nicolini F, Agostinelli A, Borrello B, Budillon AM, Bacciottini F, et al. Mini-cardiopulmonary bypass system: results of a prospective randomized study. Ann Thorac Surg. 2006;81:1396-400.

27. Remadi JP, Rakotoarivello Z, Marticho P, Trojette F, Benamar A, Poulain H, et al. Aortic valve replacement with the minimal extracorporeal circulation (Jostra MECC System) versus standard cardiopulmonary bypass: a randomized prospective trial. J Thorac Cardiovasc Surg. 2004;128:436-41.

28. Castiglioni A, Verzini A, Pappalardo F, Colangelo N, Torracca L, Zangrillo A, et al. Minimally invasive closed circuit versus standard extracorporeal circulation for aortic valve replacement. Ann Thorac Surg. 2007;83:586-91.

29. Belge KU, Dayyani F, Horelt A, Siedlar M, Frankenberger M, Frankenberger B, et al. The proinflammatory $\mathrm{CD} 14+\mathrm{CD} 16+\mathrm{DR}++$ monocytes are a major source of TNF. J Immunol. 2002;168:3536-42.

30. Todd I, Radford PM, Ziegler-Heibrock L, Ghaemmaghami AM, Powell RJ, Tighe PJ. Elevated CD16 expression by monocytes from patients with tumor necrosis factor receptor-associated periodic syndrome. Arthritis Rheum. 2007;56: 4182-8. 